\title{
A Study on Tourism Development Strategy of Kaohsiung City in Taiwan after Urban Style Regeneration
}

\section{Kun-Yao Hung, Ming-Hung Lin, and Sung-Lin Hsueh}

Graduate Institute of Cultural and Creative Design, Tung Fang Design of University, Kaohsiung, Taiwan

\section{Abstract}

Urban tourism has gradually been emphasized in past years; especially, it is regarded as a savior of urban regeneration in old industrial cities. When losing the competitive advantages and getting declined, old industrial cities are facing the challenge of transformation. The development of urban tourism is considered as the opportunity of industrial cities in dark recession that they start to involve in the development of tourism. Analytic Hierarchy Process (AHP) is applied in this study to evaluate key

Corresponding Author: Ming-Hung Lin mhlin@mail.tf.edu.tw

Received: 29 August 2018 Accepted: 18 September 2018 Published: 11 November 2018

Publishing services provided by Knowledge E

(c) Kun-Yao Hung et al. This article is distributed under the terms of the

Attribution License, which permits unrestricted use and redistribution provided that the original author and source are credited.

Selection and Peer-review under the responsibility of the ICOI-2018 Conference Committee.

\section{G OPEN ACCESS} success factors in the tourism development strategy of Kaohsiung City after the urban style regeneration. AHP is used for confirming the levels of various evaluation factors. The first hierarchy contains four evaluation dimensions, and 14 evaluation standards are covered in the second hierarchy. The results reveal the important sequence of four evaluation factors in the second hierarchy as (1) marketing activity, (2) management strategy, (3) recreational environment, and (4) infrastructure, where the importance of evaluation factors in the third hierarchy is sequenced as (1) urban attraction, (2) environmental facility maintenance, (3) celebrations, (4) local characteristics, and (5) natural landscape. The research results and suggestions in this study are expected to enhance the tourism development of Kaohsiung City in Taiwan after the urban style regeneration.

Keywords: urban style, tourism development strategy, key success factors, Delphi method, AHP

\section{Introduction}

Under the industrial structure changes of economics, Taiwan is facing the crises of industry migration and deindustrialization. Currently encountered industrial development dilemma in Taiwan is not a special case in the world. Under the economic globalization started in late zoth century, new international division of labor accelerated various industrial cities experiencing the industrial transformation after deindustrialization; Taiwan appeared no exception. In the process, urban tourism gradually became a 
major strategy of local government developing the economics. Economic globalization gradually strengthened the competition among cities that a lot of cities enhanced the attraction by utilizing undeveloped resources or producing new image. Under such a development trend, the application of existing cultural and historical resources to develop urban tourism for re-shaping urban image becomes a worth-discussion issue. Increasing disposable income and leisure time of family, the enhancement of education attainment, people's attitude changes in work and leisure, the increase in population mobility, and reducing communication costs caused by fierce market competition stimulated the explosive growth of tourism market after 1960s [1]. World Tourism Organization estimated that the increasing international passenger volume in 19952020 would grow with the speed of average $4.1 \%$ annually by 2020 , Asia and Pacific regions, in which Taiwan belonged, would be 6.5\%, which followed Middle East (7.1\%), to become the second tourist market with rapid growth in the world. Nevertheless, in spite that tourism presented development potential, some statements did not identify tourism as the factor in urban development, and even regarded it as the additional revenue of local development. Overall speaking, urban tourism has not received deserved emphases. Tourism development in Taiwan is not satisfactory; especially, international tourism still requires improvement. Research on urban tourism development in Taiwan should be more emphasized.

The Kaohsiung City used to be listed as the focus of industrial economic development to shape the image of heavy industry city in Taiwan. Since the urban planning, Kaohsiung City was positioned as "arms industry city" that it naturally became an industrial city. Along with Kaohsiung citizens' enhancing requirement for the quality of life, various cultural facilities and activities were increasing in Kaohsiung City, and the promotion of art activities gradually presented the effectiveness. Nonetheless, the continuously generated art energy could not be cumulated and the growing population of art appreciation was limited that the art environment in Kaohsiung seemed to be lack of activeness; "cultural desert" was still a stereotype of Kaohsiung City. Urban style regeneration and transformation were required for Kaohsiung City. When some old industrial cities in the world successfully regenerated with urban tourism, the idea of tourism to save Kaohsiung emerged. The Kaohsiung City Government experienced, in 2008, that the development of Kaohsiung Harbor could effectively enhance the overall infrastructure of Kaohsiung City, a series of harbor regeneration construction were promoted, expecting to have Kaohsiung Harbor become a new prosperity zone in Asia. The first promotion was piers 1-22 in Kaohsiung Harbor, to promote five major infrastructures of marine culture and pop music center, international conference and 
exhibition center, international port travel area, public library, and waterside light rail transit based on original Fisherman's Wharf, Banana Pier, the Pier-2 Art Center, private tour terminal, Lover Pier, Glory Pier, and Cijin Fishing Port. More than 30 billion NT dollars were invested, and the constructions were completed in 2013-2015. Kaohsiung City and the new tourism environment were created from a brand-new internationalization aspect to have Kaohsiung Harbor become "Asia's New Bay Area". It was expected to drive business opportunities of supporting industries and land development, trade, residential, hotel, and recreational tourism to introduce more employment opportunities and economic yield for Kaohsiung City.

Although the development and establishment of Asia's New Bay Area in Kaohsiung could enhance the development of emerging industries, e.g. cloud, digital contents, culture and creativity, music, movies and television, yacht, waterfront tourism, and conference and exhibition, how to further attract domestic and international investors would test the marketing ability of the Kaohsiung City Government. Furthermore, it is a primary issue for the Kaohsiung City Government applying urban marketing strategies and expanding the international visibility of Kaohsiung to become an international city through the development of Asia's New Bay Area.

For the permanent success of tourism development, rational identity is essential; and, such identity requires planers' comprehensive understanding of local citizens' ideas and opinions. However, Kaohsiung citizens merely passively participate in the new appearance of the urban tourism development created by the Government but have few opportunities to express the opinions. This study therefore expects to organize different relevant research to discuss tourism development strategies for Kaohsiung City after the urban style regeneration and apply AHP to verify key success factors in such tourism development strategies.

\section{Literature Review}

\subsection{Background of urban tourism development}

According to Maitland [2], urban tourism emerged in North America, transmitted to West Europe, and recently was popular in Australia, New Zealand, and Singapore to become an important element in contemporary urban economic plans. The past promotion of cities to investors was gradually transferred into the sales of cities as a consumption location. Swarbrooke [3] noticed that such tourism based urban regeneration became the mainstream in past two decades. Moreover, there were 3 reasons 
for urban tourism being long-term neglected. (1) Most research on urban tourism focused on tourism activities internal a city. (2) Planers, commercial benefit groups, and local citizens could not agree with tourism being a factor in urban development and even regarded it as additional income. (3) Urban tourism presented the characteristics of temporariness, seasonality, and short cycle that public and private sectors often neglected the study on urban tourism [4]. Ashworth [5] pointed out double neglect of urban tourism development where those stressing on tourism neglected the tourism action in cities; similarly, those focusing on urban studies neglected the tourism function of cities. Research on such theories was still weak. A lot of comprehensive research on urban tourism tended to spatiality, while the relationship between urban construction and tourism was gradually emphasized. In spite that theories about urban tourism were still short, it was an important tool to understand urban tourism. A lot of research provided several issues related to cities $[1,4-8]$.

Urban tourism was gradually emphasized in 1980s, because (1) a lot of old cities encountered the trouble of deindustrialization, which resulted in losing job opportunities in manufacturing, storage, and transportation industries, increased unemployment rate, and left lots of abandoned bases, especially in inner cities, (2) meanwhile, worldwide tourists appeared largely low increase, while tourism was regarded as a growing industry [7-9]. Accordingly, old industrial cities experienced the declination, and the public sectors started to appear interests in tourism, as it might show the potential of supporting urban redevelopment, especially in city centers and inner cities. English Tourist Board therefore started to encourage local organizations studying the potential of tourism creating employment rate [8]. Since 1990, many European tourism cities, such as London, York, Venice, and Florence, appeared tourism fever that public and private sectors gradually regarded tourism as an industry with development potential $[6,8]$.

Till early 1990s, the existence of urban tourism became the academic discussion topic [4]; in middle and late 1990s, the supply and demand [10, 11], process, policy, and plan for urban tourism were emphasized that urban tourism was gradually covered in academic research [12]. Regarding the research structure of urban tourism, Ashworth [5] questioned "the existence of urban tourism" and pointed out three urban tourism research methods. (1) Supply of urban tourism: It stressed on tourism facilities in cities. (2) Demand for urban tourism: It contained motivation, perception, and behavior. (3) Policy of urban tourism: It included public and private sectors. The above was merely the preliminary categories. A decade later, Pearce [9], in consideration of urban tourism 
as an emerging research subject and the relevant research being lack of uniform integration structure, proposed the integrated structure for research on urban tourism.

\subsection{Essence of urban tourism}

Ashworth [4] pointed out four characteristics of cities to regard urban tourism as a study. (1) High-density aggregation of buildings, people, and activities. (2) Heterogeneity of society and culture. (3) Multi-functional economy. (4) Centrality in the network between regions and cities. Pearce [9] considered that such characteristics resulted in inevitably complicated development of urban tourism to make leisurefocused places (e.g. seaside and in the mountains) show distinct characteristics. Tourism was merely one of the activities in a city where tourists and citizens shared or strove for service, space, and facilities. Besides, a city did not simply play a role in tourism, but could be the door, a stopover, a touring spot, and tourism resource. The emergence of urban tourism presented great relationship with urban regeneration; nevertheless, researchers from the aspect of urban regeneration and those from the aspect of urban tourism formed two different schools. Researchers in the urban regeneration school observed from reality. For instance, Gómez [12] discussed the image transfer of two industrial cities, Glasgow in UK and Bilbao in Spain, and regarded the remarkable enhancement of employment rate as the measuring indicator of successful urban regeneration. On the other hand, advocates of urban tourism stressed on the strong meaning of tourism bringing for urban regeneration. Collinge [13] indicated that investment in tourism contained the improvement of local facilities and environment as well as the delivery of marketing and tourism image to promote the attraction of industry or business activities. The change in image would result in middle-class citizens returning cities and visitors' consumption on facilities or activities to generate more economic profits through multiplier effect. Finally, the improvement of facilities and environment, the urban regeneration, and the visit of tourists might enhance the citizens' sense of honor to pay more efforts to the environment [7]

Shaw and Williams [14] indicated that complete urban facilities and concentrated locations of indoor touring spots could satisfy visitors and local citizens' needs. The diversity of urban touring spots had researchers start to study the uniqueness and similarities of touring spots in cities. Shaw and Williams [14] defined three methods of (1)diversity of cities, (2)multi-function of towns, and (3)tourism function of a town not simply being generated or used when there were tourists, but because of various users in the city. Aiming at the essence of a tourism city, Judd and Fainstein [15] 
proposed the opinions and classified them into (1)resort cities, (2)tourist-historic cities, and (3)converted cities, which purposively constructed infrastructure to attract visitors. The difference between two schools was that a city regarded tourism as a method of urban regeneration or an industry. When urban tourism was regarded as a tool, the actual situations should be taken into account, especially economic effect, e.g. reducing unemployment rate and enhancing average income. When urban tourism was regarded as an industry, the concern would transfer to the derived benefits, e.g. beautification of environment and facilities and citizens' sense of honor. Coles and Shaw [16] considered that, for most urban citizens, the benefit resulted from tourism development was not necessary the economic income, but the improvement of living quality.

\subsection{System of urban tourism}

Tourism was regarded as a "system" $[6,17]$ used for researchers comprehending the essence of tourism, aiming to rationalize and simplify complicated tourism in real societies and transform tourism into several concepts and compositions to emphasize the internal essence of tourism.

When urban tourism had to undertake the responsibility of urban regeneration, Law [7] advocated that it was necessary to constantly enhance the attraction of tourism resources for the sustainable management. From the aspect of supply-demand, Jansen-Verbeke [18] classified tourism resources into 3 categories. (1) The major element was the body to attract visitors, including two sub-categories. One was the activity location, such as cultural facilities (theaters, music hall, cinemas, and art gallery), entertainment sites (casinos), activities, carnivals, exhibitions, and artwork places. The other was leisure environment, including physical environment of historic relics, monuments, memorial halls, parks, and waterfront piers, and social cultural characteristics of language, local customs, and lifestyles. (2) The secondary elements to enhance or increase attraction to visitors, containing shopping, catering service, and accommodation. (3) Additional elements of accessibility, transportation facilities, and tourism information. Law [7] explained the relationship between cities and tourism and indicated that regarding the marketing of tourism as "a part of local economic policies" might be wrong, as the investment in tourism involved in equipment, physical environment, and infrastructure, which would benefit the places; and, the construction of facilities, the redevelopment of the places, and the arrival of visitors would enhance 
"civic pride", which was considered as a good thing. Research revealed that local citizens with "civic pride" would take more care of the environment.

\subsection{Key success factor}

Key Success Factors (KSF) is also named Critical Success Factors (CSF). Barnard [19] applied key success factors to manage decision-making theories and considered that the analysis required for decision-making was to look for strategic factors. Hofer \& Schendel [20] pointed out key success factors as the variables with which the management could determine the overall competition positioning of various companies in the industry. Such variables would change with industries, and key success factors in specific industry were generated by the interaction of two variables, i.e. economic and technological characters included in the industry as well as the competitive strategies established by different companies in the industry. Tillett [21] applied the idea of strategic factors to the theory of dynamic organizational systems and regarded critical resources as the most resources in an organization; and, the meaning of strategy was to maintain and well apply the advantage from the most resources and to avoid the weakness resulted from the lack of certain resources. Rockart [22] proposed that key success factors existed in few fields of an enterprise; once such fields were properly done, the enterprise could present better competitive performance; and, such primary fields could be the reference for high-level managers deciding the information required for the enterprise. Leidecker \& Bruno [23] pointed out key success factors as correctly supporting, maintaining, or managing characteristics, situations, or variables which presented major influence on the success of a company in specific industry. Ferguson \& Dickinson [24] indicated that key success factors were (1) internal/external factors of an enterprise which should be confirmed and carefully handled, as such factors would affect the enterprise achieving the goal and even threaten the survival of the enterprise, (2) such businesses or conditions showed particularly significant effects on the enterprise, (3) which might be internal or external factors of the enterprise, (4) the effects on the enterprise might be positive or negative, and (5) could be confirmed by evaluating the strategies, environment, resources, operation, or other fields of the enterprise. Boynton \& Zmud [25] proposed that enterprise should particularly and continuously pay attention to key success factors in order to present good performance or success. Key success factors contained major factors in the success of current or future operation activities. Aaker [26] referred key success factors as an enterprise with better assets and capability than other enterprises to win the competitive assets 
or capability in the market. A study on the industry with one to six mature products revealed that key success factors would change with industries; meanwhile, manufacturers with key success factors normally presented better performance than other enterprises. An enterprise had to confirm key success factors as well as used such factors for predicting major success elements that might appear in the future. In terms of industrial products, technology and innovation were the key factors in introduction and growth stages, while system capacity, marketing, and after-sales service were required for the mature stage. For consumption products, marketing and distribution skills were particularly important in introduction and growth stages, while operation and manufacturing processes were focused in mature and recession stages.

\section{Research Method}

\subsection{Research structure}

Multi-criteria Decision is used for the selection of key success factors in the tourism development strategy for Kaohsiung City after the urban style regeneration. To solve the problem, Modified Delphi Method and AHP are applied to such non-structured problems. Traditional Delphi Method could easily appear the shortcomings of time consuming, high cost, and low retrieval rate of questionnaire for collecting experts' opinions. Moreover, the so-called consistent expert opinions appear merely when the opinions are in certain range; however, fuzziness is covered in the range but is not taken into account. Besides, in the process for consistency, expert opinions are easily distorted, i.e. systematically weakening the other opinions and inhibiting different ideas [27]. Delphi Method requires several runs of questionnaire survey, which is time and energy consuming to reduce the retrieval rate. Murry \& Hammons [28] therefore developed "Modified Delphi Method", which presented the spirit and advantage of Delphi Method and showed similar practice and statistics as traditional Delphi Method, but simplified the complicated questionnaire process. In other words, it omitted openended questionnaire survey, but replaced it with research results from literatures or the researchers' planning. After the revision with pretest, a structured questionnaire was directly developed, or expert interview replaced the first-run survey. Such a method could save time and budget as well as enhance the retrieval rate of questionnaire; besides, the structured questionnaire could have the participants focus on the research questions. 
This study aims to gradually converge complicated data toward definite dimensions, sub-goals, and various evaluation criteria to construct the AHP structure; Modified Delphi Method could solve such a problem. AHP is an inevitable method to solve multi-criteria decision problems; besides, AHP is the most commonly used method in decision-making field. It shows simple structure, allows decision-makers easily expressing the preference, and could ensure the consistency of the preference that AHP could acquire the weights of various evaluation criteria. Among various literatures on key success factors in the tourism development strategy after urban style regeneration, it is listed with variables with high significance. With Modified Delphi Method, the diagram of Analytic Hierarchy Process is shown in Fig.1.

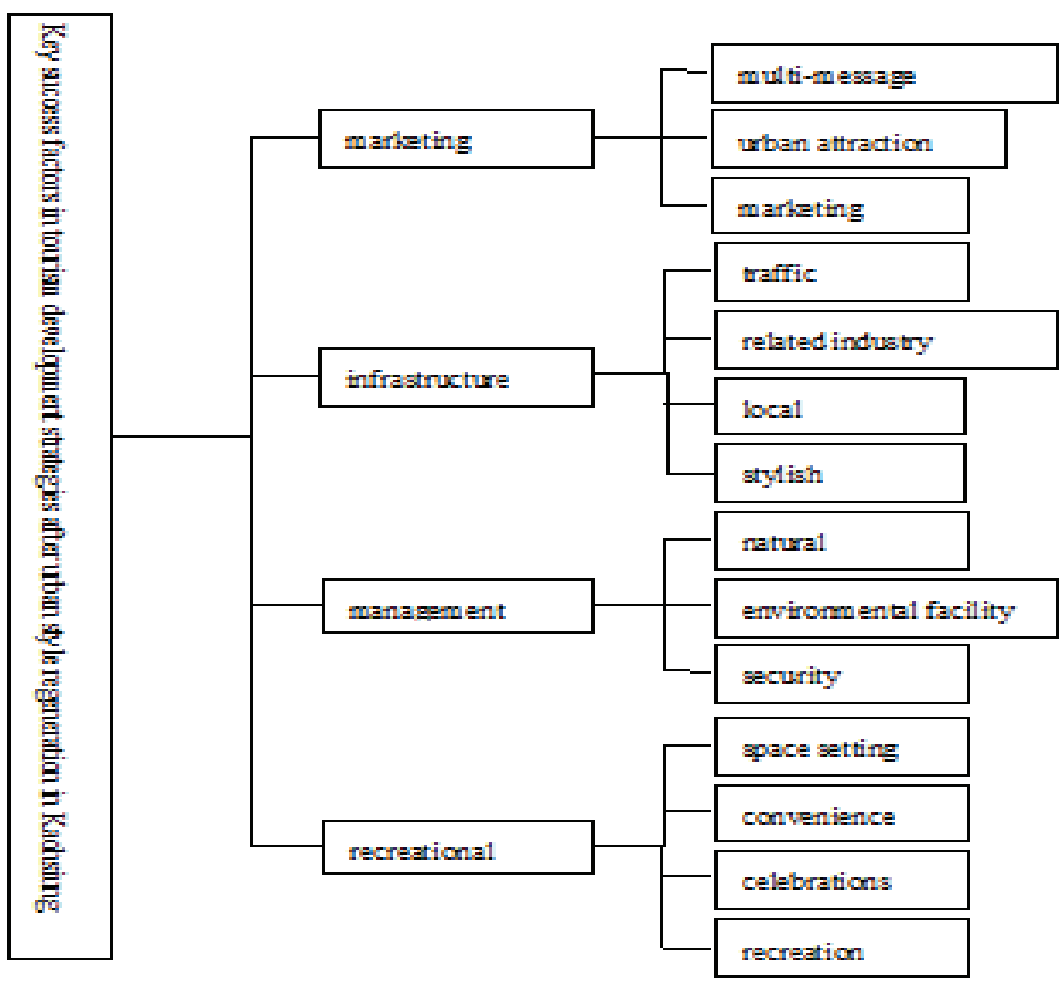

Figure 1: Evaluation structure map.

\subsection{Pretest questionnaire}

For the pretest, 55 copies of questionnaire are distributed to 11 objects, including 10 universities and departments related to tourism as well as the Kaohsiung City Government. The retrieved questionnaire is organized and analyzed the shortcomings. 


\subsection{Questionnaire distribution and retrieval}

Total 380 copies of formal questionnaire are distributed to the public in 38 administrative districts in Kaohsiung City, with 10 copies for each administrative district. After retrieving the questionnaire, 106 invalid copies are removed, and total 274 copies are valid, with the retrieval rate $72 \%$.

\subsection{Questionnaire distribution and retrieval}

Table I lists the weights and the ranking of evaluation elements with overall consistency acquired with Expert Choice 2000. The result shows the acceptable standard of the consistency, where urban attraction is mostly emphasized, followed by environmental facility maintenance, and space setting is least emphasized.

TABLE 1: Weights of evaluation elements with overall consistency of Analytic Hierarchy Process and the ranking.

\begin{tabular}{|c|c|c|c|c|}
\hline & \begin{tabular}{|lcr} 
Hierarchy & 1 & evaluation \\
element (hierarchical weight)
\end{tabular} & $\begin{array}{l}\text { Hierarchy } 2 \text { evaluation element } \\
\text { (hierarchical weight) }\end{array}$ & $\begin{array}{c}\text { overall weight } \\
\text { (Global priority) }\end{array}$ & ranking \\
\hline \multirow{14}{*}{$\begin{array}{l}\text { key success } \\
\text { factors in the } \\
\text { tourism } \\
\text { development } \\
\text { strategy of } \\
\text { urban style } \\
\text { regeneration } \\
\lambda \max =4.662 \\
\text { C.I. }=0.003 \\
\text { C.R. }=0.008\end{array}$} & \multirow{3}{*}{$\begin{array}{l}\text { marketing activity } \\
(0.326)\end{array}$} & $\begin{array}{l}\text { multi-message } \\
\text { communication } 0.315\end{array}$ & 0.091 & 6 \\
\hline & & urban attraction 0.438 & 0.132 & 1 \\
\hline & & marketing content 0.247 & 0.082 & 8 \\
\hline & \multirow{4}{*}{$\begin{array}{l}\text { infrastructure } \\
(0.159)\end{array}$} & traffic infrastructure 0.184 & 0.051 & 13 \\
\hline & & $\begin{array}{|ll|}\begin{array}{l}\text { related } \\
\text { development } 0.242\end{array} & \text { industry } \\
\end{array}$ & 0.064 & 11 \\
\hline & & local characteristics 0.298 & 0.102 & 4 \\
\hline & & stylish characteristics 0.276 & 0.076 & 9 \\
\hline & \multirow{3}{*}{$\begin{array}{l}\text { management strategy } \\
(0.297)\end{array}$} & natural landscape 0.339 & 0.095 & 5 \\
\hline & & $\begin{array}{|ll|}\text { environmental } & \text { facility } \\
\text { maintenance } 0.367 & \\
\end{array}$ & 0.124 & 2 \\
\hline & & security mechanism 0.294 & 0.058 & 12 \\
\hline & \multirow{4}{*}{$\begin{array}{l}\text { recreational environment } \\
(0.218)\end{array}$} & space setting 0.197 & 0.048 & 14 \\
\hline & & convenience 0.271 & 0.086 & 7 \\
\hline & & celebrations 0.304 & 0.116 & 3 \\
\hline & & recreation facility 0.228 & 0.068 & 10 \\
\hline
\end{tabular}




\section{Conclusion}

With AHP to analyze the research structure, the result shows the importance sequence of four evaluation elements in the second hierarchy as (1)marketing activity, (2)management strategy, (3)recreational environment, and (4)infrastructure. Apparently, marketing activity is the most important key success factor in the tourism development strategy of urban style regeneration in Kaohsiung City. The importance of the evaluation criteria in the third hierarchy is ranked (1)urban attraction, (2)environmental facility maintenance, (3)celebrations, (4)local characteristics, and (5)natural landscape. Obviously, the development of global tourism and tourism activities are booming. Local governments therefore develop local resources through hardware construction and culture shaping to combine local industries to attract enterprises co-constructing and planning the city. It does not simply improve the image of the city, enhance the living standard of the city, and shape local and cultural \& creative characteristics, but also drives the economic development of the city. Urban attraction is the extrinsic performance of intrinsic quality of a city that urban attraction and marketing could be promoted through environmental facility maintenance, development of local characteristic industries, provision of caring service for visitors, and shaping local cultural image.

The future tourism of Kaohsiung could be developed through the creation of unique and elaborative concepts and the combination with business and art. By creating the environment suitable for people, promoting unique urban styles, combining the power of word-of-mouth, and having domestic tourists as the short-term goals to enhance the urban style to a certain level, the target market could then be promoted to the international tourism stage to attract tourists who would like to experience different cities and aesthetics.

\section{References}

[1] Van der Berg, L., Van der Borg, J. \& Van der Meer, J., " Urban Tourism: Performance and Strategies in Eight European Cities," Aldershot, England: Avebury, 1995.

[2] Maitland, R., "How can we manage the tourist-historic city? Tourism strategy in Cambridge, UK, 1978-2003", Tourism Management, vol.27, pp.1262-1273, 2006.

[3] Swarbrooke, J., Sustainable Tourism Management, Wallingford, UK: CABI.

[4] Ashworth, G. J., "Is there an Urban Tourism?," Tourism Recreation Research, vol.17, no.2, pp. 3-8, 1992. 
[5] Ashworth, G. J., "Urban Tourism: an Imbalance in Attention," In C. P. Cooper, (Eds.) Progress in Tourism, Recreation and Hospitality Management, vol.1, pp.3354, London: Belhaven Press, 1989.

[6] Page, S., Urban Tourism, London: Routledge, 1995.

[7] Law, C. M., "Urban Tourism and Its Contribution to Economic Regeneration," Urban Studies, vol.29, nos. 3-4, pp. 599-618, 1992.

[8] Law, C. M., Urban Tourism: The Visitor Economy and the Growth of Large Cities, London: Continuum, 2002.

[9] Pearce, D., "An Integrative Framework for Urban Tourism Research," Annals of Tourism Research, vol.28, no.4, pp.926-946, 2001.

[10] Law, C. M., Urban Tourism: Attracting Visitors to Large Cities. London: Mansell, 1993.

[11] Law, C. M. (Eds.), Tourism in Major Cities. London: International Thomson Business Press, 1996.

[12] Gómez, M. V., "Reflective Images: The Case of Urban Regeneration in Glasgow and Bilbao," International Journal of Urban and Regional Research, vol.22(1), pp.106-121, 1998.

[13] Collinge, M., Tourism and urban regeneration. Vision for Cities, London: ETB, 1989.

[14] Shaw, G. \& Williams, A., Critical issues in tourism A geographical perspective. Oxford Blackwell, 1994.

[15] Judd D. R. \& Fainstein S. S., The Tourist City, Yale University Press, New Haven and London, 1999.

[16] Coles, L.C., \& P.E. Shaw., "PAK1 primes MEK1 for phosphorylation by Raf-1 kinase during cross-cascade activation of the ERK pathway," Oncogene. 21:2236-2244, 2002.

[17] Gunn, C. A., Tourism Planning: Basics, Concepts and Cases. New York: Taylor and Francis, 1993.

[18] Jansen-Verbeke, M., "Inner-City Tourism: Resources, Tourists and Promoters," Annals of Tourism Research, vol.13(1), pp.79-100, 1986.

[19] Barnard, C.r.I., The Functions of the Executive. Harvard University Press, Cambridge. Mass., pp.185-205, 1976.

[20] Hofer, Charles W. \& Schendel, Dan E., Strategy Formulation Analytical Concepts, West Publishing Company, St. Paul. Minnesota, 1978.

[21] Tillett, B. B., Authority control in the online environment, Haworth Press, New York, 1989. 
[22] Rockart, J. F. (1979), Chief Executives Define Their Own Data Needs. Harvard Business Review, Mar.-Apr., pp.81-92.

[23] Leidecker, Joel K. \& Bruno, Albert V., "Identifying and Using Critical Success Factors," Long Range Planning,Vol.17, no.4, pp.23-32, 1984.

[24] Ferguson, Charles R. \& Dickinson, Roger, "Critical Success Factor For Directors in the Eighties," Business Horizons. May-June, pp.14-18, 1982.

[25] Boynton, Andrew C. \& Zmud, Robert W., "An Assessment of Critical Success Factors," Sloan Management Review, Vol.25, no.4, pp.17-27, 1984.

[26] Aaker, D. A., Strategic Market Management. John Wiley \& Sons Inc., New York, 1988.

[27] Hwang, C.L., Lin, M.L., Group Decision Making Under Multiple Criteria Method and Application.Springer-Verlag, Reading.Berlin Heidelberg, 1987.

[28] Murry, J. W. \& Hommons, J. 0., "Delphi: A versatile methodology for conducting qualitative research," The Review of Higher Education, vol.18, no.4, Pp.423-436, 1995 . 